Annals of Pure and Applied Mathematics

Vol. 16, No. 1, 2018, 171-176

ISSN: 2279-087X (P), 2279-0888(online)

Published on 11 January 2018

www.researchmathsci.org

DOI: http://dx.doi.org/10.22457/apam.v16n1a18

Annals of

Pure and Applied

Mathematics

\title{
Prime Cordial Labeling of Some Graphs Related to H-Graph
}

A. Sugumaran ${ }^{1}$ and V. Mohan ${ }^{2}$

Department of Mathematics

Government Arts College

Thiruvannamalai-606603, Tamil Nadu, India.

1e-mail: sugumaran3@yahoo.com

2e-mail: vmb5685@gmail.com

Received 21 November 2017; accepted 26 December 2017

Abstract. A prime cordial labeling of a graph $\mathrm{G}$ with vertex set $\mathrm{V}(\mathrm{G})$ is a bijection $\mathrm{f}$ : $\mathrm{V}(\mathrm{G}) \rightarrow\{1,2,3, \ldots,|V(G)|\}$ such that each edge uv is assigned the label 1 if $\operatorname{gcd}(\mathrm{f}(\mathrm{u})$, $\mathrm{f}(\mathrm{v}))=1$ and 0 if $\operatorname{gcd}(\mathrm{f}(\mathrm{u}), \mathrm{f}(\mathrm{v}))>1$, then the number of edges labeled with 0 and the number of edges labeled with 1 differ by at most 1 . A graph which admits prime cordial labeling is called prime cordial graph. In this paper, we prove that the graphs $\mathrm{H}_{1} \mathrm{~K}_{1}$, $\mathrm{P}(\mathrm{r} . \mathrm{H}), \mathrm{C}(\mathrm{r} . \mathrm{H})$ and $\mathrm{S}(\mathrm{r} . \mathrm{H})$ are prime cordial.

Keywords: Prime cordial labeling, H-graph, path union, cycle union and open star of graphs.

\section{AMS Mathematics Subject Classification (2010): 05C78}

\section{Introduction}

We consider only simple, finite, undirected and non-trivial graph $G=(V(G), E(G))$ with the vertex set $V(G)$ and the edge set $E(G)$. The number of elements of $V(G)$, denoted as $|\mathrm{V}(\mathrm{G})|$ while the number of elements of $\mathrm{E}(\mathrm{G})$, denoted as $|\mathrm{E}(\mathrm{G})|$. For standard terminology and notations we follow Harary [3]. A graph labeling is an assignment of labels to edges, vertices or both. Cahit. I [1] introduced the concept of cordial labeling in 1987. The concept of cordial labeling was extended to divisor cordial labeling, sum divisor cordial labeling, prime cordial labeling, total cordial labeling, etc., A survey of graph labeling, we refer to Gallian [2].

Vaidya and Shah [10] proved that, some star and bistar related graphs are divisor cordial graphs. Duplication of vertices and edges was introduced by Vaidya and Barasara [9] and they applying this concept to the product cordial graphs. Sugumaran and Rajesh [5] have shown that, Swastik graph $S_{n}$, some graph operations related to Swastik graph, Jelly fish J(n, n) and Petersen graph are sum divisor cordial graphs. Sugumaran and Rajesh [6] proved that Theta graphs and some operations of Theta graph are sum divisor cordial graphs. Sundaram et al. [8] introduced the concept of prime cordial labeling. Sugumaran and Prakash [7] proved that one point union of path of Theta graphs, open 


\section{A. Sugumaran and V. Mohan}

star of Theta graphs and path union of even copies of Theta graph are prime cordial graphs.

Sugumaran and Mohan [4] have proved prime cordial labeling of the graphs such as butterfly graph, W-graph, H-graph and duplication of edges of an H-graph. In section 2, we summarize the necessary definitions and notations which are useful for the present work. In section 3, we proved that the graphs such as $\mathrm{H}^{\circ} \mathrm{K}_{1}$, path union of $\mathrm{r}$ copies of $\mathrm{H}-$ graph, cycle union of $r$ copies of $\mathrm{H}$-graph and open star of $r$ copies of $\mathrm{H}$-graph are prime cordial graphs. An application of graph labeling is discussed in [11].

\section{Definitions}

In this section, we will provide a brief summary of definitions, which are necessary for the present investigation.

Definition 2.1. A mapping $\mathrm{f}: \mathrm{V}(\mathrm{G}) \rightarrow\{0,1\}$ is called binary vertex labeling of $\mathrm{G}$ and $\mathrm{f}(\mathrm{v})$ is called the label of the vertex $v$ of $G$ under $f$.

Definition 2.2. A binary vertex labeling $\mathrm{f}$ of a graph $\mathrm{G}$ is called a cordial labeling if $\mid \mathrm{v}_{\mathrm{f}}(0)$ $-\mathrm{v}_{\mathrm{f}}(1) \mid \leq 1$ and $\left|\mathrm{e}_{\mathrm{f}}(0)-\mathrm{e}_{\mathrm{f}}(1)\right| \leq 1$, where

$$
\begin{aligned}
& v_{f}(i)=\text { number of vertices of } G \text { having label } i \\
& e_{f}(i)=\text { number of edges of } G \text { having label } i
\end{aligned}
$$

Definition 2.3. [8]A prime cordial labeling of $G$ with vertex set $V(G)$ is a bijection $f$ : $\mathrm{V}(\mathrm{G}) \rightarrow\{1,2,3, \ldots,|V(G)|\}$ such that each edge uv is assigned the label 1 if $\operatorname{gcd}(\mathrm{f}(\mathrm{u})$, $\mathrm{f}(\mathrm{v}))=1$ and 0 if $\operatorname{gcd}(\mathrm{f}(\mathrm{u}), \mathrm{f}(\mathrm{v}))>1$, then the number of edges labeled with 1 and the number of edges labeled with 0 differ by at most 1 . A graph which admits prime cordial labeling is called prime cordial graph.

Definition 2.4. The graph $H \odot K_{l}$ is obtained by adding a pendant edge to each vertex of an H-graph.

Definition 2.5. The path union of a graph $G$ is the graph obtained from a path $P_{n}(n \geq 2)$ by replacing each vertex of the path by graph $G$ and it is denoted by $P(n . G)$.

Definition 2.6. The cycle union of a graph $\mathrm{G}$ is the graph obtained from a cycle $\mathrm{C}_{\mathrm{n}}(\mathrm{n} \geq$ 3) by replacing each vertex of the cycle by graph $G$ and it is denoted by C(n.G).

Definition 2.7. The open star of a graph $\mathrm{G}$ is the graph obtained from a star graph $\mathrm{K}_{1, \mathrm{n}}$ $(n \geq 2)$ by replacing each vertex(except the apex vertex) of the star by graph $\mathrm{G}$ and it is denoted by $S(n \cdot G)$.

\section{Main results}

In this section, we proved that some of the graphs related to H-graph are prime cordial graphs.

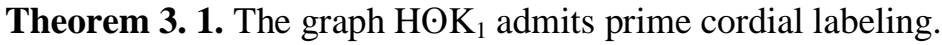


Prime Cordial Labeling of Some Graphs Related to H-Graph

Proof: Consider an $\mathrm{H}$ graph with $2 \mathrm{n}$ vertices. Let $\mathrm{G}=\mathrm{H}_{\mathrm{O}}$. Let $\mathrm{V}(\mathrm{H})=\left\{u_{i}, v_{i}: 1\right.$ $\leq i \leq n\}$. Let $u_{1}^{\prime}, u_{2}^{\prime}, u_{3}^{\prime}, \ldots, u_{n}^{\prime}$, be the pendant vertices connected to $u_{1}, u_{2}, u_{3}, \ldots, u_{n}$ respectively and let $v_{1}^{\prime}, v_{2}^{\prime}, v_{3}^{\prime}, \ldots, v_{n}^{\prime}$, be the pendant vertices connected to $v_{1}, v_{2}, v_{3}, \ldots, v_{n}$ respectively in $\mathrm{G}$. Then $|\mathrm{V}(\mathrm{G})|=4 \mathrm{n}$ and $|\mathrm{E}(\mathrm{G})|=4 \mathrm{n}-1$. We define the vertex labeling function $\mathrm{f}: \mathrm{V}(\mathrm{G}) \rightarrow\{1,2,3, \ldots, 4 n\}$ as follows.

$\mathrm{f}\left(u_{i}\right)=4 \mathrm{i}-3 ; 1 \leq i \leq n$.

$\mathrm{f}\left(v_{i}\right)=4 \mathrm{i}-2 ; 1 \leq i \leq n$.

$\mathrm{f}\left(u_{i}^{\prime}\right)=4 \mathrm{i}-1 ; 1 \leq i \leq n$.

$\mathrm{f}\left(v_{i}^{\prime}\right)=4 \mathrm{i} \quad ; 1 \leq i \leq n$. In view of the labeling pattern defined above, we have $\mid \mathrm{e}_{\mathrm{f}}(0)$ - $\mathrm{e}_{\mathrm{f}}(1) \mid \leq 1$. Hence $\mathrm{G}$ is a prime cordial graph.

Example 3. 1. Prime cordial labeling of the graph $\mathrm{H}_{5} \odot \mathrm{K}_{1}$ is shown in Figure 1.

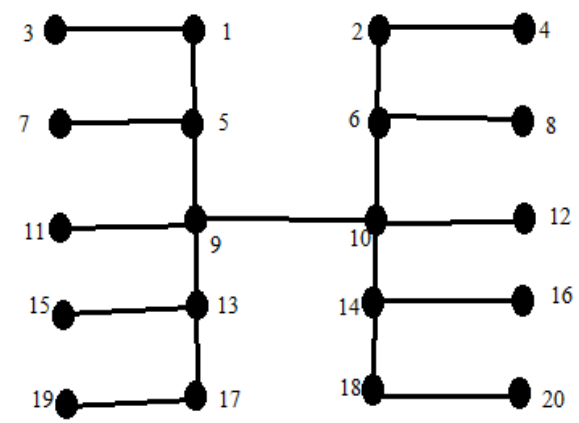

Figure 1: Prime cordial labeling of $\mathrm{H}_{5} \odot \mathrm{K}_{1}$

Theorem 3.2. The Path union of $\mathrm{r}$ copies of H-graph is a prime cordial graph.

Proof: Consider an $\mathrm{H}$-graph with $2 \mathrm{n}$ vertices. Let $\mathrm{G}=\mathrm{P}(\mathrm{r} . \mathrm{H})$ be the Path union of $\mathrm{r}$ copies of $H$-graph. In graph $\mathrm{G},|\mathrm{V}(\mathrm{G})|=2 \mathrm{nr}$ and $|\mathrm{E}(\mathrm{G})|=2 \mathrm{nr}-1$. We denote $u_{i}^{k}$ and $v_{i}^{k}$ are the $i^{t h}$ vertex in the $k^{t h}$ copy of the first and second path in the H-graph respectively, where $\mathrm{i}=1,2,3, \ldots, \mathrm{n}$ and $\mathrm{k}=1,2,3, \ldots, \mathrm{r}$. Notice that the vertices $v_{1}^{k}$ and $v_{1}^{k+1}$ are connected by an edge in $\mathrm{G}$, where $\mathrm{k}=1,2,3, \ldots, \mathrm{r}-1$. To define the vertex labeling function $\mathrm{f}: \mathrm{V}(\mathrm{G}) \rightarrow\{1,2,3, \ldots, 2 n r\}$ as follows.

$\mathrm{f}\left(u_{i}^{k}\right)=2 \mathrm{i}-1 ;(\mathrm{k}-1) \mathrm{n}+1 \leq i \leq k n, \mathrm{k}=1,2,3, \ldots, \mathrm{r}$.

$\mathrm{f}\left(v_{i}^{k}\right)=2 \mathrm{i} \quad ;(\mathrm{k}-1) \mathrm{n}+1 \leq i \leq k n, \mathrm{k}=1,2,3, \ldots, \mathrm{r}$.

If $\mathrm{n}$ is even, then we interchange the labels of the vertices $v_{\frac{n}{2}}^{k}$ with $v_{\frac{n}{2}+1}^{k}, \mathrm{k}=1,2,3, \ldots$, r. In view of the labeling pattern defined above, we have $\left|e_{f}(0)-e_{f}(1)\right|=1$. Hence $G$ is a prime cordial graph.

Example 3. 2. Prime cordial labeling of the graph $\mathrm{P}\left(3 . \mathrm{H}_{4}\right)$ is shown in Figure 2. 


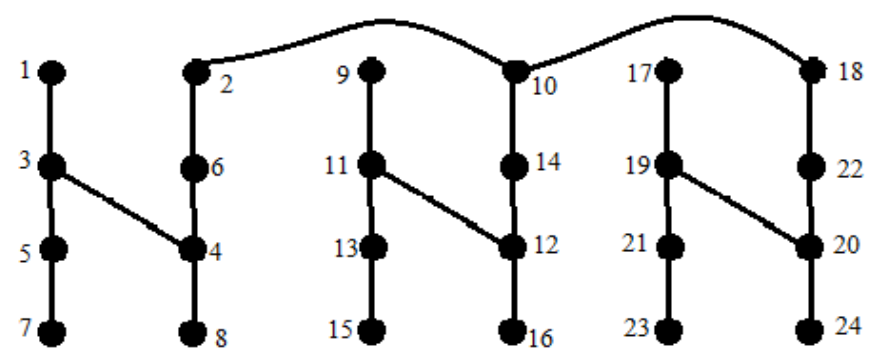

Figure 2: Prime cordial labeling of graph $\mathrm{P}\left(3 . \mathrm{H}_{4}\right)$

Theorem 3.3. The Cycle union of $\mathrm{r}$ copies of an H-graph is a prime cordial graph.

Proof: Consider an H-graph with $2 n$ vertices. Let $\mathrm{G}=\mathrm{C}(\mathrm{r} . \mathrm{H})$ be the cycle union of $\mathrm{r}$ copies of $\mathrm{H}$-graph. In graph $\mathrm{G},|\mathrm{V}(\mathrm{G})|=2 \mathrm{nr}$ and $|\mathrm{E}(\mathrm{G})|=2 \mathrm{nr}$. We denote $u_{i}^{k}$ and $v_{i}^{k}$ are the $i^{\text {th }}$ vertex in the $k^{t h}$ copy of the first and second path in the H-graph respectively, where $\mathrm{i}=1,2,3, \ldots, \mathrm{n}$ and $\mathrm{k}=1,2,3, \ldots, \mathrm{r}$. Notice that the vertices $v_{1}^{k}$ and $v_{1}^{k+1}$ are connected by an edge and the vertices $v_{1}^{r}$ and $v_{1}^{1}$ are connected by an edge in $\mathrm{G}$, where $\mathrm{k}$ $=1,2,3, \ldots, \mathrm{r}-1$. To define the vertex labeling function $\mathrm{f}: \mathrm{V}(\mathrm{G}) \rightarrow\{1,2,3, \ldots, 2 \mathrm{nr}\}$ as follows.

$\mathrm{f}\left(u_{i}^{k}\right)=2 \mathrm{i}-1 ;(\mathrm{k}-1) \mathrm{n}+1 \leq i \leq k n, \mathrm{k}=1,2,3, \ldots, \mathrm{r}$.

$\mathrm{f}\left(v_{i}^{k}\right)=2 \mathrm{i} \quad ;(\mathrm{k}-1) \mathrm{n}+1 \leq i \leq k n, \mathrm{k}=1,2,3, \ldots, \mathrm{r}$.

If $\mathrm{n}$ is even, then we interchange the labels of the vertices $v_{\frac{n}{2}}^{k}$ with $v_{\frac{n}{2}+1}^{k}, \mathrm{k}=1,2,3, \ldots$, r. In view of the labeling pattern defined above, we have $\left|e_{f}(0)-e_{f}(1)\right|=0$. Hence $G$ is a prime cordial graph.

Example 3.3. Prime cordial labeling of the graph $\mathrm{C}\left(4 . \mathrm{H}_{3}\right)$ is shown in Figure 3.

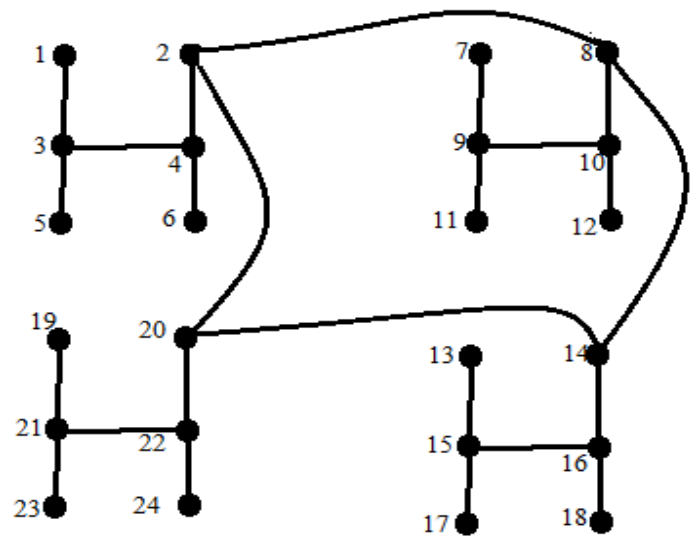

Figure 3: Prime cordial labeling of $\mathrm{C}\left(4 . \mathrm{H}_{3}\right)$

Theorem 3.4. The Open star of $r$ copies of an $\mathrm{H}$-graph is a prime cordial graph.

Proof: Consider an H-graph with $2 \mathrm{n}$ vertices. Let $\mathrm{G}=\mathrm{S}(\mathrm{r} . \mathrm{H})$ be the open star of $\mathrm{r}$ copies of $\mathrm{H}$-graph. In graph $\mathrm{G},|\mathrm{V}(\mathrm{G})|=2 \mathrm{nr}+1$ and $|\mathrm{E}(\mathrm{G})|=2 \mathrm{nr}$. We denote $u_{i}^{k}$ and $v_{i}^{k}$ are the $i^{t h}$ vertex in the $k^{\text {th }}$ copy of the first and second path of the H-graph respectively, where $\mathrm{i}=1,2,3, \ldots, \mathrm{n}$ and $\mathrm{k}=1,2,3, \ldots, \mathrm{r}$. Let $\mathrm{w}$ be the apex vertex of $\mathrm{G}$. Also we join the 
Prime Cordial Labeling of Some Graphs Related to H-Graph

vertices $v_{1}^{k}$ with $\mathrm{w}$ by an edge in $\mathrm{G}$, where $\mathrm{k}=1,2,3, \ldots, \mathrm{r}$. We define the vertex labeling function $\mathrm{f}: \mathrm{V}(\mathrm{G}) \rightarrow\{1,2,3, \ldots, 2 n r+1\}$ as follows.

$\mathrm{f}\left(u_{i}^{k}\right)=2 \mathrm{i}-1 ;(\mathrm{k}-1) \mathrm{n}+1 \leq i \leq k n, \mathrm{k}=1,2,3, \ldots, \mathrm{r}$.

$\mathrm{f}\left(v_{i}^{k}\right)=2 \mathrm{i} \quad ;(\mathrm{k}-1) \mathrm{n}+1 \leq i \leq k n, \mathrm{k}=1,2,3, \ldots, \mathrm{r}$.

$\mathrm{f}(\mathrm{w})=2 \mathrm{nr}+1$.

If $\mathrm{n}$ is even, we interchange the labels of the vertices $v_{\frac{n}{2}}^{k}$ with $v_{\frac{n}{2}+1}^{k}, \mathrm{k}=1,2,3$, $\ldots, \mathrm{r}$ and further we interchange the labels of the vertices $\mathrm{w}$ with $v_{n}^{r}$. In view of the labeling pattern defined above, we have $\left|e_{\mathrm{f}}(0)-\mathrm{e}_{\mathrm{f}}(1)\right|=1$. Hence $\mathrm{G}$ is a prime cordial graph.

Example 3. 4. Prime cordial labeling of the graph $\mathrm{S}\left(4 . \mathrm{H}_{3}\right)$ is shown in Figure 4.

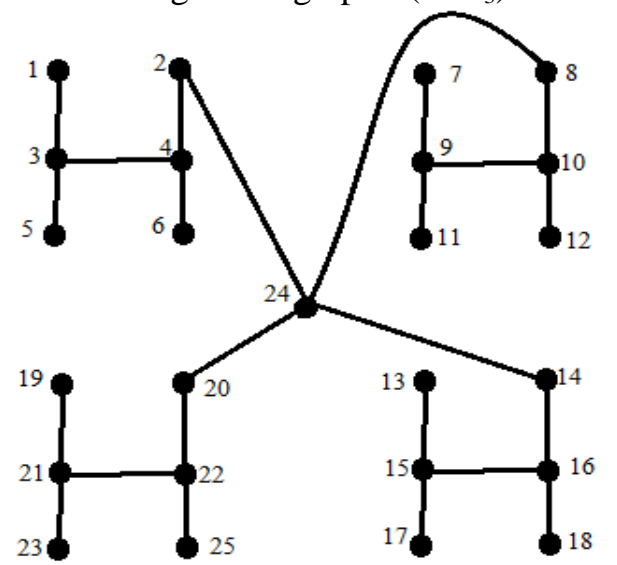

Figure 4: Prime cordial labeling of $\mathrm{S}\left(4 . \mathrm{H}_{3}\right)$

\section{Conclusion}

$\mathrm{H}$-graph is one of the interesting graphs in graph theory. In this paper we proved that the graphs such as $\mathrm{H \odot K}_{1}$, path union of $\mathrm{r}$ copies of H-graph, cycle union of $\mathrm{r}$ copies of $\mathrm{H}$ graph and open star of $\mathrm{r}$ copies of $\mathrm{H}$-grah are prime cordial graphs. Extending our results to various other graph operations related to $\mathrm{H}$-graph is an interesting open area of research.

Acknowledgement. We are very grateful to the anonymous referees for their valuable suggestions to improve this paper in its present form.

\section{REFERENCES}

1. I.Cahit, Cordial graphs: A weaker version of graceful and harmonious graphs, Ars Combinatoria, 23 (1987) 201 - 207.

2. J.A.Gallian, A dynamic survey of graph labeling, The Electronic Journal of Combinatorics, 18 (2011), \#DS6.

3. F.Harary, Graph theory, Narosa Publishing House, (2001).

4. A.Sugumaran and V.Mohan, Further results on prime cordial labeling, Annals of Pure and Applied Mathematics, 14 (3) (2017) 489 - 496. 


\section{A. Sugumaran and V. Mohan}

5. A.Sugumaran and K.Rajesh, Some new results on sum divisor cordial graphs, Annals of Pure and Applied Mathematics, 14 (1) (2017) 45 - 52.

6. A.Sugumaran and K.Rajesh, Sum divisor cordial labeling of theta graph, Annals of Pure and Applied Mathematics, 4 (2) (2017) 313 - 320.

7. A.Sugumaran and P.Vishnu Prakash, Some new results on prime cordial labeling for theta graph, Journal of Computer and Mathematical Science, 8 (11) (2017) 630 634.

8. M.Sundaram, R.Ponraj, S.Somasundaram, Prime cordial labeling of graphs, Journal of Indian Academy of Mathematics, 27 (2015) 373 - 390.

9. S.K.Vaidya and Barasara, Product cordial graphs in the context of some graph operations, International Journal of Mathematics and Scientific Computing, 1 (2011) 1 - 6.

10. S.K.Vaidya and N.H.Shah, Some star and bistar related divisor cordial graphs, Annals of Pure and Applied Mathematics, 3 (1) (2013) 67 - 77.

11. A.Saha, M.Pal and T.K.Pal, Selection of programme slots of television channels for giving advertisement: A graph theoretic approach, Information Sciences, 177 (12) (2007) 2480-2492. 